\title{
Blood profiling of proteins and steroids during weight maintenance with manipulation of dietary protein level and glycaemic index
}

Ping Wang ${ }^{1}$, Claus Holst ${ }^{2}$, Arne Astrup ${ }^{3}$, Freek G. Bouwman ${ }^{1}$, Sanne van Otterdijk ${ }^{1}$, Will K. W. H. Wodzig ${ }^{4}$, Malene R. Andersen ${ }^{5}$, Marleen A. van Baak ${ }^{1}$, Lone G. Rasmussen ${ }^{3}$, J. Alfredo Martinez ${ }^{6}$, Susan A. Jebb ${ }^{7}$, Andreas F. H. Pfeiffer ${ }^{8,9}$, Anthony Kafatos ${ }^{10}$, Teodora Handjieva-Darlenska ${ }^{11}$, Petr Hlavaty ${ }^{12}$,

Wim H. M. Saris ${ }^{1}$ and Edwin C. M. Mariman ${ }^{1 *}$ on behalf of Diogenes Consortium $\dagger$

${ }^{1}$ Department of Human Biology, NUTRIM School for Nutrition, Toxicology and Metabolism, Maastricht University Medical Centre, PO 616, 6200 MD Maastricht, The Netherlands

${ }^{2}$ Institute of Preventive Medicine, Copenhagen University Hospital, Copenhagen, Denmark

${ }^{3}$ Department of Human Nutrition, Faculty of Life Sciences, University of Copenhagen, Copenhagen, Denmark

${ }^{4}$ Department of Clinical Chemistry, Maastricht University Medical Centre, Maastricht, The Netherlands

${ }^{5}$ Department of Clinical Biochemistry, Copenhagen University Hospital, Gentofte, Denmark

${ }^{6}$ Department of Physiology and Nutrition, University of Navarra, Pamplona, Spain

${ }^{7}$ MRC Human Nutrition Research, Elsie Widdowson Laboratory, Cambridge, UK

${ }^{8}$ Department of Clinical Nutrition, German Institute of Human Nutrition, Nuthetal, Germany

${ }^{9}$ Department of Endocrinology, Diabetes and Nutrition, Charité Universitaetsmedizin Berlin, Berlin, Germany

${ }^{10}$ Department of Social Medicine, Preventive Medicine and Nutrition Clinic, University of Crete, Crete, Greece

${ }^{11}$ Department of Nutrition, Dietetics and Metabolic Diseases, National Multiprofile Transport Hospital, Sofia, Bulgaria

${ }^{12}$ Obesity Management Centre, Institute of Endocrinology, Prague, The Czech Republic

(Received 16 December 2010 - Revised 15 March 2011 - Accepted 25 March 2011 - First published online 23 June 2011)

\section{Abstract}

Weight regain after weight loss is common. In the Diogenes dietary intervention study, a high-protein and low-glycaemic index (GI) diet improved weight maintenance. The objective of the present study was to identify (1) blood profiles associated with continued weight loss and weight regain (2) blood biomarkers of dietary protein and GI levels during the weight-maintenance phase. Blood samples were collected at baseline, after 8 weeks of low-energy diet-induced weight loss and after a 6-month dietary intervention period from female continued weight losers $(n$ 48) and weight regainers ( $n$ 48), evenly selected from four dietary groups that varied in protein and GI levels. The blood concentrations of twenty-nine proteins and three steroid hormones were measured. The changes in analytes during weight maintenance largely correlated negatively with the changes during weight loss, with some differences between continued weight losers and weight regainers. Increases in leptin (LEP) and C-reactive protein (CRP) were significantly associated with weight regain $(P<0.001$ and $P=0.005$, respectively), and these relationships were influenced by the diet. Consuming a high-protein and highGI diet dissociated the positive relationship between the change in LEP concentration and weight regain. CRP increased during the weight-maintenance period only in weight regainers with a high-protein diet $(P<0 \cdot 001)$. In addition, testosterone, luteinising hormone, angiotensinogen, plasminogen activator inhibitor-1, resistin, retinol-binding protein 4 , insulin, glucagon, haptoglobin and growth hormone were also affected by the dietary intervention. The blood profile reflects not only the weight change during the maintenance period, but also the macronutrient composition of the dietary intervention, especially the protein level.

Key words: Blood hormones: Dietary intervention: Obesity: Weight-loss maintenance

Abbreviations: AGT, angiotensinogen; CID1, clinical investigation day before weight loss; CID2, clinical investigation day after weight loss; CID3, clinical investigation day after weight maintenance; CRP, C-reactive protein; \%E, percentage of energy; GCG, glucagon; GH, growth hormone; GI, glycaemic index; HGI, high glycaemic index; HP, high protein; IGFBP1, insulin-like growth factor binding protein 1; INS, insulin; LEP, leptin; LGI, low glycaemic index; LH, luteinising hormone; LP, low protein; PAI1, plasminogen activator inhibitor 1; RBP4, retinol-binding protein 4; TES, testosterone; WL, continued weight losers; WR, weight regainers.

*Corresponding author: Professor Dr Edwin C. M. Mariman, fax +31 43 3670976; email e.mariman@maastrichtuniversity.nl

† Diogenes is the acronym of the project 'Diet, Obesity and Genes' supported by the European Commission (contract no. FP6-2005-513946), http://www.diogenes-eu.org/. 
The worldwide epidemic of obesity and related health problems including diabetes demands profound measures to help overweight and obese people to reduce their weight and maintain a healthier reduced weight ${ }^{(1,2)}$. Compared with weight loss, weight maintenance after weight loss requires a continuous long-term effort to battle weight regain that commonly occurs ${ }^{(3)}$. Medical treatments, physical activity, and also dietary intervention have been shown to be capable of improving the success rate of weight maintenance ${ }^{(4)}$. Manipulating the macronutrient content, particularly by increasing the protein content, has shown some benefit on preventing weight regain ${ }^{(5)}$. In addition, a low-glycaemic index (GI) diet may favour a healthy metabolic profile ${ }^{(6)}$.

The Diogenes programme is a pan-European project targeting the obesity problem by dietary intervention. In this programme, the relative efficacy of four different diets with variation in protein:carbohydrate ratio and GI level was investigated with respect to weight-loss maintenance in European families with overweight and obese parents ${ }^{(7,8)}$. It showed that both a modestly higher protein content and a modest reduction in GI in the context of an ad libitum diet improve weight-loss maintenance ${ }^{(9)}$.

To understand the biological processes underlying the physiological outcome of weight maintenance on different diets, a systematic profiling of the body is useful. Since the ongoing physiological activities of all tissues are reflected in it, blood is an important source for discovering biomarkers $^{(10)}$. Here, we investigated thirty-two proteins and steroid hormones in the blood of women who participated in the Diogenes dietary intervention study. The profiling of these targeted adipokines, cytokines, inflammation markers, vascular factors, satiety hormones, sex hormones and other metabolic hormones, in a search for their relationship with weight regain or weight loss during intended weight maintenance, and their relationship with dietary protein and GI levels, helps to get an insight into the differences in weight maintenance when manipulating dietary protein and GI intake.

\section{Subjects and methods}

\section{Subjects and study design}

The participants were part of the pan-European, multicentre, randomised and controlled dietary intervention study Diogenes (http://www.diogenes-eu.org, ClinicalTrials.gov registration no.: NCT00390637). The design and dietary intervention have been described in detail previously ${ }^{(7-9)}$. The study was conducted according to the guidelines laid down in the Declaration of Helsinki and all procedures involving human subjects were approved by the local ethical committees in the respective countries: (1) Medical Ethics Committee of the University Hospital Maastricht and Maastricht University, The Netherlands; (2) The Committees on Biomedical Research Ethics for the Capital region of Denmark, Denmark; (3) Suffolk Local Research Ethics Committee, UK; (4) University of Crete Ethics Committee, Greece; (5) the Ethics Commission of the University of
Potsdam; (6) Research Ethics Committee at the University of Navarra, Spain; (7) Ethical Committee of the Institute of Endocrinology, Czech Republic; (8) Ethical Committee to the National Transport Multiprofile Hospital in Sofia, Bulgaria. Written informed consent was obtained from all subjects.

In brief, the study was composed of two phases: a weightloss phase and a weight-maintenance phase with dietary intervention. Overweight or obese but otherwise healthy subjects followed an 8-week, low-energy diet with about $3 \cdot 3-4 \cdot 2 \mathrm{MJ} / \mathrm{d}$. Those who achieved $\geq 8 \%$ loss of initial body weight were in a $2 \times 2$ factorial design randomised to one of the following four moderate-fat ad libitum diets or a control diet for 6-month weight maintenance with dietary counselling every $2-4$ weeks $^{(7)}$ : diet 1 , low protein (LP) and low GI (LGI) (LP/LGI); diet 2, LP and high GI (HGI) (LP/HGI); diet 3, high protein (HP) and LGI (HP/LGI); diet 4, HP and HGI (HP/HGI). Participants were advised to maintain their weight loss during this phase, but there were no restrictions with respect to further weight reduction.

The anthropometrical and physiological parameters were measured on clinical investigation day (CID) 1 before weight loss, CID2 after weight loss and CID3 after weight maintenance. The subjects were not given a standard diet the day before CID, but were asked not to consume any food or liquids except for $350-500 \mathrm{ml}$ water at least $10 \mathrm{~h}$ before the investigation. The majority of the participants had their fat mass measured by dual-emission X-ray absorptiometry scan or bioelectrical impedance analysis. Blood, urine and fat biopsy samples were collected at each centre using the same standardised protocols ${ }^{(8)}$. For the present study, EDTA plasma and serum samples in the fasting state were divided into aliquots and kept at $-80^{\circ} \mathrm{C}$ during storage and transportation. In addition, serum glucose, TAG, cholesterols, dietary intake based on food diaries, and urinary analysis of $24 \mathrm{~h} \mathrm{~N}$ excretion to assess adherence to the diet were measured as described previously ${ }^{(8,9)}$

The sample size estimation of the complete Diogenes study has been described previously ${ }^{(9)}$. As in previous studies $^{(11,12)}$, to avoid biological variation caused by ethnicity and sex, we focused on Caucasian female participants, who were below 50 years of age, non-diabetic and non-dyslipidaemic, taking one of the four intervention diets (selection criteria shown in Fig. 1). Considering facility capacity and assay cost, based on a 'weight-maintenance score' we selected ninety-six subjects in total, which is about half of the eligible subjects after removing extremes with the lowest and highest 10th percentile of the score from each diet group, which might have an overwhelming effect by their large body-weight change on other biological processes. From each dietary group, twelve subjects with relatively the highest weight reduction during the 6-month maintenance period (continued weight losers (WL)) and twelve subjects with relatively the highest weight regain in that period (weight regainers (WR)) were studied (Fig. 1).

A power calculation showed that assuming a standard deviation of $50 \%$ of the mean value of the variable, if such a ninety-six-subject design would enter three-way ANOVA, the power would be 0.80 to detect a main-effect difference 


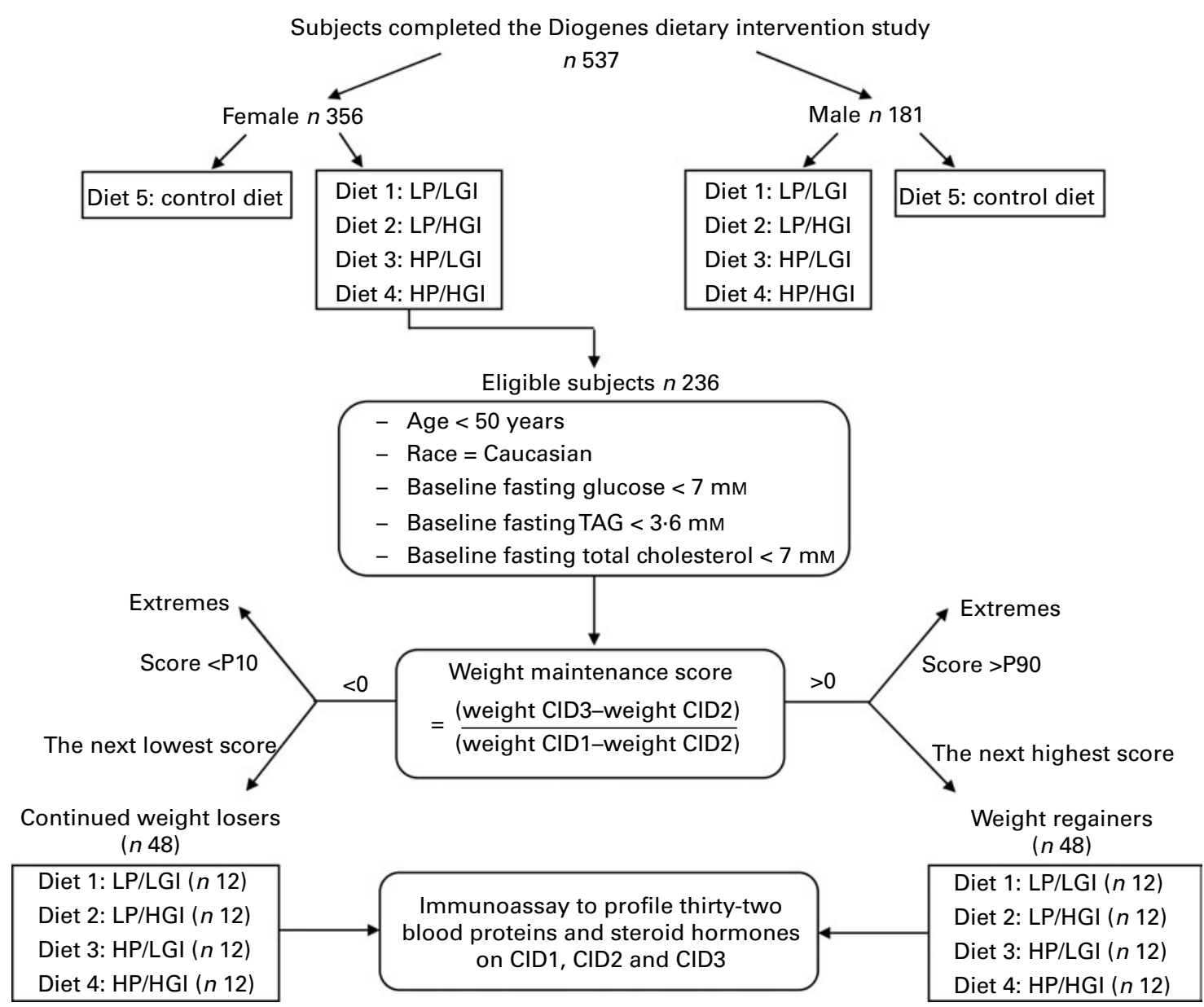

Fig. 1. Schematic representation of the experimental design and subject selection. CID1, baseline, before weight loss; CID2, after 8-week weight loss; CID3, after 6-month weight maintenance; Gl, glycaemic index; HP, high protein; LP, low protein; LGI, low Gl; HGI, high GI; P10, 10th percentile; P90, 90th percentile.

at a two-sided 0.05 significance level, when the true difference between the groups is $29 \%$. For the two-factor interaction, the power would be 0.80 , when the difference is $50 \%$. For the three-factor interaction, the power would be 0.80 , when the difference is $81 \%$.

\section{Measurement of targeted blood factors}

The selection of blood analytes as targets is described in the supplementary material (available online at http://www. journals.cambridge.org/bjn). All the samples were blinded and randomly allocated with respect to dietary intervention and weight change before transport to the laboratories for analysis. The majority of the analytes were analysed in plasma, unless otherwise stated, by two multiplex biomarker testing laboratories with Clinical Laboratory Improvement Amendments certification: Rules-Based Medicine (Austin, TX, USA), applying their Human Metabolic Map version 1.0 (http://www.rulesbasedmedicine.com/products-services/ human-metabolic.asp), and SearchLight (Aushon BioSystems, Woburn, MA, USA), applying a customised multiplex immunoassay. The remaining analytes were analysed in-house, as in the previous study ${ }^{(11)}$.

\section{Data analysis}

Analytes by multiplex assays were excluded if more than half of the samples were not measurable on the standard curve or with high variation in controls. The final list of included analytes is shown in Table 1 . The values of insulin-like growth factor 1 of $16 \%$ of the samples and the values of growth hormone (GH) of $6 \%$ of the samples, which were flagged as being below the detection limit, were imputed with a value of half of the lowest detected concentration. The data of plasma insulin (INS) measured by Rules-Based Medicine were calibrated using INS data from a subset of serum samples as described previously $^{(11)}$. Furthermore, outliers defined as a data point out of the mean $\pm 4 \mathrm{sD}$ range were removed for each analyte.

The anthropometrical and physiological parameters that were all normally distributed are expressed as means and standard deviations. The fold changes during weight loss and maintenance were evaluated by the ratio of the values in CID2:CID1 and CID3:CID2, respectively. For blood analytes, the natural logarithm-transformed concentration and fold changes were used for analyses

Univariate data analysis was done with SPSS version 15.0 (SPSS, Inc., Chicago, IL, USA). Mean dietary intakes were 
Table 1. List of analysed proteins and steroid hormones in plasma and serum

\begin{tabular}{|c|c|c|c|}
\hline Category & Symbol & Name & Executed \\
\hline \multirow[t]{5}{*}{ Sex hormones } & PRO & Progesterone & Rules-Based Medicine \\
\hline & TES & Testosterone & Rules-Based Medicine \\
\hline & $\mathrm{LH}$ & Luteinising hormone & Rules-Based Medicine \\
\hline & FSH & Follicle-stimulating hormone & Rules-Based Medicine \\
\hline & PRL & Prolactin & Rules-Based Medicine \\
\hline Other steroid hormone & COR & Cortisol & Rules-Based Medicine \\
\hline \multirow[t]{3}{*}{ Vascular factors } & ACE & Angiotensin I converting enzyme 1 & Rules-Based Medicine \\
\hline & AGT & Angiotensinogen & Rules-Based Medicine \\
\hline & PAl1 & Plasminogen activator inhibitor- 1 , active & Aushon SearchLight \\
\hline \multirow[t]{5}{*}{ Adipokines } & LEP & Leptin & Rules-Based Medicine \\
\hline & RETN & Resistin & Rules-Based Medicine \\
\hline & ASP & Acylation-stimulating protein & Rules-Based Medicine \\
\hline & ADIPOQ & Adiponectin & Rules-Based Medicine \\
\hline & RBP4 & Retinol-binding protein 4 & Aushon SearchLight \\
\hline \multirow[t]{3}{*}{ Insulin and related hormones } & INS & Insulin & Rules-Based Medicine \\
\hline & GCG & Glucagon & Rules-Based Medicine \\
\hline & IAPP & Islet amyloid polypeptide, amylin, total & In-house \\
\hline \multirow[t]{7}{*}{ Immunoproteins } & MIF & Macrophage migration inhibiting factor & Aushon SearchLight \\
\hline & IL-6 & Interleukin 6 & In-house \\
\hline & IL-8 & Interleukin 8 & In-house \\
\hline & TNF- $\alpha$ & Tumour necrosis factor $\alpha$ & In-house \\
\hline & MMP9 & Matrix metallopeptidase 9 & In-house* \\
\hline & HPT & Haptoglobin & In-house* \\
\hline & CRP & C-reactive protein & In-house* \\
\hline \multirow[t]{6}{*}{ Growth factors } & $\mathrm{GH}$ & Growth hormone & Aushon SearchLight \\
\hline & IGF1 & Insulin-like growth factor 1 & Rules-Based Medicine \\
\hline & VEGFD & Vascular endothelial growth factor-D & Aushon SearchLight \\
\hline & PEDF & Pigment epithelium-derived factor & Aushon SearchLight \\
\hline & IGFBP1 & Insulin-like growth factor binding protein 1 & Aushon SearchLight \\
\hline & IGFBP3 & Insulin-like growth factor binding protein 3 & Aushon SearchLight \\
\hline \multirow[t]{2}{*}{ Satiety hormones } & GLP1 & Glucagon-like peptide-1, total & Rules-Based Medicine \\
\hline & PP & Pancreatic polypeptide & Rules-Based Medicine \\
\hline
\end{tabular}

* Analysed in serum. Others in plasma.

compared by the $t$ test. For anthropometrical and physiological parameters, the difference between the WL and WR groups in CID1, CID2 and the CID2:CID1 ratio were analysed by the $t$ test. The differences in the fold change during the weightmaintenance period were analysed by one-way ANOVA with respect to weight loss or regain, with the CID2:CID1 ratio as a covariate. The effects of dietary protein and GI on the changes in body weight and body fat were analysed by twoway ANOVA with the CID2:CID1 ratio as a covariate in the WL and WR groups separately.

The relationship between the fold changes in blood analytes during weight loss and weight maintenance was evaluated by Pearson's correlation. The fold changes in blood analytes during the maintenance period were analysed in a multi-way ANOVA using the outcome of maintenance (WL or WR), dietary protein (low and high), and dietary GI (low and high) as fixed factors, and with or without age, weight CID2:CID1 ratio and the CID2:CID1 ratio of the analyte as COvariates. The $P$ values were further controlled for false discovery rate in multiple testing with the Benjamini-Hochberg method $^{(13)}$ using the 'stats' package in $\mathrm{R}$ (version 2.10.1; http://www.r-project.org/ $)^{(14)}$. The fixed factor in multi-way ANOVA with a $P<0.03$, equivalent to multiple testing $q<0 \cdot 25$, was taken as significant. In other cases, a two-side $P<0.05$ was taken as significant.

To explore the relationships between the fold changes in anthropometry, physical parameters and biochemical analytes during the weight-maintenance phase, we used multivariate data analysis with the software GeneMaths XT version 2.12 (Applied Maths, Sint-Martens-Latem, Belgium). Supervised discriminant principal component analysis was applied to the fold changes in all anthropometrical and physiological parameters, and measured blood proteins and steroids, on participants nested in eight maintenance and diet groups. The missing values were first imputed by the $K$ nearest-neighbours method within the program. Grouped subjects with LP or HP, and LGI or HGI were also shown in the principal component analysis score plot as group profiles. A variable with a loading score $>2$ or a geometric mean of the loading score on all components $>3$ was taken as an important contributor.

\section{Results}

\section{Subjects' characteristics}

From the Diogenes dietary intervention study, ninety-six overweight/obese but otherwise healthy women (age 29-49 years), who had the most pronounced (but not extreme) WL or WR after weight loss according to the weight-maintenance score, were selected evenly from four dietary groups. In the pooled subjects, the WL and WR groups did not differ with regard to anthropometrical and physiological characters at baseline (CID1) nor after weight loss (CID2), and only showed a trend $(P=0.057)$ for younger age in the WL group 
Table 2. Characteristics of the study subjects by diet and the outcome of weight maintenance at baseline (CID1), after 8-week weight loss (CID2) and after 6-month maintenance intervention (CID3)* (Mean values and standard deviations)

\begin{tabular}{|c|c|c|c|c|c|c|c|c|c|c|c|c|c|c|c|c|c|c|c|c|c|}
\hline \multirow[b]{3}{*}{ Parameters } & \multirow[b]{3}{*}{ Time } & \multicolumn{4}{|c|}{ Pool } & \multicolumn{4}{|c|}{ Diet 1, LP/LGI } & \multicolumn{4}{|c|}{ Diet 2, LP/HGI } & \multicolumn{4}{|c|}{ Diet 3, HP/LGI } & \multicolumn{4}{|c|}{ Diet 4, $\mathrm{HP} / \mathrm{HGl}$} \\
\hline & & \multicolumn{2}{|c|}{ WL ( $n$ 48) } & \multicolumn{2}{|c|}{ WR ( $n$ 48) } & \multicolumn{2}{|c|}{ WL $(n 12)$} & \multicolumn{2}{|c|}{ WR $(n 12)$} & \multicolumn{2}{|c|}{ WL $(n 12)$} & \multicolumn{2}{|c|}{ WR $(n 12)$} & \multicolumn{2}{|c|}{ WL $(n 12)$} & \multicolumn{2}{|c|}{ WR ( $n$ 12) } & \multicolumn{2}{|c|}{$\mathrm{WL}(n 12)$} & WR & 12) \\
\hline & & Mean & SD & Mean & SD & Mean & SD & Mean & SD & Mean & SD & Mean & SD & Mean & SD & Mean & SD & Mean & SD & Mean & SD \\
\hline $\begin{array}{l}\text { Weight-maintenance } \\
\text { score }\end{array}$ & & -0.28 & 0.14 & 0.42 & 0.12 & -0.31 & 0.11 & 0.43 & 0.10 & -0.17 & 0.10 & 0.52 & 0.11 & -0.36 & 0.20 & 0.38 & 0.11 & -0.30 & 0.08 & 0.33 & 0.10 \\
\hline Age (years) & & 39.3 & $5 \cdot 3$ & $41 \cdot 3$ & 5.0 & $43 \cdot 0$ & 5.8 & $41 \cdot 1$ & 3.8 & 38.3 & 3.6 & $42 \cdot 9$ & 3.6 & 38.4 & 4.4 & $39 \cdot 3$ & $6 \cdot 0$ & 37.4 & 5.6 & 41.8 & 6.0 \\
\hline Weight (kg) & CID1 & 97.5 & $16 \cdot 4$ & $93 \cdot 3$ & $12 \cdot 6$ & $101 \cdot 3$ & 18.5 & 98.9 & $10 \cdot 8$ & $87 \cdot 3$ & 6.9 & 91.9 & $12 \cdot 8$ & $104 \cdot 5$ & $16 \cdot 4$ & 91.6 & $16 \cdot 2$ & 96.7 & $17 \cdot 3$ & 91.0 & 9.3 \\
\hline & CID2 & $86 \cdot 3$ & 14.6 & 83.8 & $11 \cdot 8$ & $89 \cdot 7$ & 17.5 & $88 \cdot 7$ & 9.8 & $78 \cdot 0$ & 7.6 & 83.1 & $12 \cdot 6$ & $91 \cdot 7$ & $14 \cdot 7$ & $81 \cdot 7$ & $15 \cdot 3$ & $85 \cdot 8$ & 14.4 & 81.5 & 8.4 \\
\hline & CID3 & 83.0 & 13.6 & 87.7 & $12 \cdot 2$ & $86 \cdot 1$ & $16 \cdot 9$ & $93 \cdot 2$ & $10 \cdot 4$ & 76.5 & 7.8 & 87.5 & 12.5 & 87.1 & 13.5 & 85.4 & $15 \cdot 9$ & 82.4 & $13 \cdot 6$ & 84.7 & $8 \cdot 2$ \\
\hline BMI $\left(\mathrm{kg} / \mathrm{m}^{2}\right)$ & CID1 & 34.5 & 4.8 & 33.3 & $4 \cdot 3$ & 35.8 & $5 \cdot 0$ & 34.6 & 4.4 & 30.9 & $2 \cdot 6$ & 33.4 & 4.4 & $36 \cdot 3$ & $4 \cdot 2$ & $32 \cdot 2$ & 4.5 & 35.0 & 5.4 & 33.0 & $4 \cdot 2$ \\
\hline & CID2 & 30.6 & $4 \cdot 3$ & 29.9 & $4 \cdot 1$ & 31.6 & 4.9 & $31 \cdot 1$ & $4 \cdot 2$ & $27 \cdot 6$ & $2 \cdot 9$ & $30 \cdot 2$ & 4.4 & 31.9 & 3.8 & 28.8 & $4 \cdot 2$ & $31 \cdot 1$ & 4.5 & 29.5 & 3.7 \\
\hline & CID3 & 29.4 & $4 \cdot 0$ & $31 \cdot 3$ & $4 \cdot 2$ & 30.4 & 4.8 & $32 \cdot 6$ & $4 \cdot 3$ & $27 \cdot 1$ & 2.9 & 31.8 & 4.5 & $30 \cdot 3$ & $3 \cdot 3$ & $30 \cdot 0$ & $4 \cdot 3$ & 29.8 & $4 \cdot 2$ & 30.6 & $3 \cdot 7$ \\
\hline Fat mass (\%) & CID1 & $44 \cdot 3$ & $5 \cdot 1$ & 43.4 & 5.4 & $45 \cdot 6$ & $4 \cdot 3$ & $45 \cdot 1$ & 5.8 & $41 \cdot 0$ & 4.9 & $44 \cdot 4$ & 4.5 & 44.8 & 5.5 & $41 \cdot 3$ & 5.5 & $45 \cdot 7$ & 4.9 & $42 \cdot 7$ & 5.8 \\
\hline & CID2 & 40.4 & $6 \cdot 1$ & 39.7 & 6.5 & $42 \cdot 7$ & 4.9 & $43 \cdot 7$ & 4.5 & 35.8 & $6 \cdot 2$ & $40 \cdot 6$ & $7 \cdot 3$ & $41 \cdot 2$ & $6 \cdot 1$ & 38.3 & $6 \cdot 7$ & 41.5 & 5.7 & 36.6 & 5.9 \\
\hline & CID3 & 37.6 & 5.8 & 40.7 & 5.7 & 37.7 & 4.9 & 41.8 & $5 \cdot 1$ & 35.0 & $5 \cdot 7$ & $43 \cdot 7$ & 5.4 & 39.5 & $5 \cdot 3$ & 39.2 & $6 \cdot 2$ & 38.4 & $7 \cdot 0$ & 39.0 & 5.6 \\
\hline Waist (cm) & CID1 & 104 & 13 & 102 & 11 & 107 & 13 & 107 & 10 & 96 & 7 & 101 & 13 & 107 & 9 & 101 & 13 & 105 & 19 & 99 & 10 \\
\hline & CID2 & 95 & 12 & 94 & 10 & 96 & 12 & 98 & 9 & 86 & 7 & 94 & 9 & 100 & 7 & 92 & 13 & 96 & 16 & 93 & 9 \\
\hline & CID3 & 91 & 12 & 97 & 10 & 93 & 14 & 103 & 9 & 87 & 8 & 98 & 10 & 93 & 9 & 93 & 10 & 93 & 15 & 95 & 9 \\
\hline Systolic blood & CID1 & 121 & 13 & 120 & 12 & 128 & 12 & 122 & 13 & 114 & 10 & 116 & 13 & 116 & 12 & 119 & 11 & 124 & 12 & 124 & 13 \\
\hline & CID2 & 116 & 12 & 114 & 13 & 123 & 12 & 115 & 12 & 110 & 11 & 110 & 15 & 113 & 10 & 118 & 11 & 119 & 14 & 114 & 13 \\
\hline & CID3 & 118 & 13 & 120 & 13 & 124 & 12 & 124 & 9 & 117 & 13 & 116 & 11 & 114 & 13 & 122 & 19 & 118 & 12 & 117 & 9 \\
\hline Diastolic blood & CID1 & 75 & 10 & 73 & 10 & 80 & 11 & 75 & 9 & 71 & 8 & 70 & 12 & 74 & 6 & 73 & 11 & 75 & 13 & 75 & 8 \\
\hline & CID2 & 71 & 9 & 71 & 11 & 73 & 7 & 74 & 12 & 69 & 11 & 68 & 8 & 70 & 8 & 75 & 12 & 73 & 11 & 69 & 10 \\
\hline & CID3 & 72 & 9 & 74 & 10 & 74 & 10 & 75 & 11 & 71 & 9 & 73 & 11 & 70 & 6 & 74 & 12 & 73 & 10 & 73 & 8 \\
\hline Cholesterol (mmol//) & CID1 & 4.6 & 0.8 & 4.6 & 1.0 & $5 \cdot 0$ & 0.8 & 4.3 & 1.4 & 4.6 & 0.8 & 4.9 & 0.9 & 4.5 & 0.9 & 4.6 & 0.7 & 4.5 & 0.7 & 4.7 & 1.0 \\
\hline & CID2 & 4.1 & 0.7 & $4 \cdot 2$ & 0.8 & $4 \cdot 3$ & 0.8 & 4.0 & 1.0 & 3.9 & 0.4 & 4.4 & 0.6 & $4 \cdot 1$ & 0.4 & 4.0 & 0.9 & 4.0 & 0.9 & $4 \cdot 2$ & 0.8 \\
\hline & CID3 & 4.5 & 0.6 & 4.8 & 0.8 & 4.7 & 0.6 & 4.8 & 0.7 & 4.5 & 0.4 & $5 \cdot 0$ & 0.7 & 4.5 & 0.6 & 4.8 & 0.9 & $4 \cdot 3$ & 0.8 & 4.8 & 0.9 \\
\hline TAG (mmol/l) & CID1 & 1.3 & 0.5 & 1.2 & 0.5 & 1.4 & 0.6 & 1.2 & 0.6 & 1.1 & 0.4 & 1.1 & 0.6 & 1.2 & 0.7 & 1.0 & 0.4 & 1.2 & 0.3 & 1.5 & 0.5 \\
\hline & CID2 & 1.1 & 0.3 & 1.1 & 0.5 & 1.1 & 0.4 & 1.2 & 0.8 & 1.0 & 0.4 & 1.0 & 0.4 & 1.1 & 0.3 & 0.9 & 0.3 & 1.1 & 0.3 & 1.3 & 0.4 \\
\hline & CID3 & 1.0 & 0.4 & $1 \cdot 2$ & 0.6 & 0.9 & 0.3 & 1.3 & 0.6 & 1.2 & 0.4 & $1 \cdot 1$ & 0.4 & 1.0 & 0.5 & 1.0 & 0.4 & 1.0 & 0.4 & 1.4 & 0.7 \\
\hline $\mathrm{HDL}(\mathrm{mmol} / \mathrm{l})$ & CID1 & $1 \cdot 3$ & 0.3 & 1.3 & 0.4 & 1.3 & 0.3 & $1 \cdot 1$ & 0.4 & 1.3 & 0.3 & 1.4 & 0.3 & 1.3 & 0.3 & 1.4 & 0.4 & 1.2 & 0.2 & $1 \cdot 1$ & 0.3 \\
\hline & CID2 & 1.2 & 0.2 & 1.2 & 0.3 & 1.2 & 0.3 & 1.1 & 0.3 & 1.2 & 0.3 & 1.3 & 0.2 & 1.2 & 0.2 & 1.3 & 0.4 & 1.1 & 0.2 & $1 \cdot 1$ & 0.2 \\
\hline & CID3 & 1.4 & 0.3 & 1.4 & 0.4 & 1.5 & 0.4 & 1.4 & 0.3 & 1.4 & 0.3 & 1.6 & 0.4 & 1.4 & 0.3 & 1.6 & 0.5 & 1.3 & 0.2 & 1.2 & 0.3 \\
\hline LDL (mmol/l) & CID1 & $2 \cdot 8$ & 0.7 & $2 \cdot 8$ & 0.8 & 3.1 & 0.7 & $2 \cdot 7$ & $1 \cdot 1$ & $2 \cdot 7$ & 0.7 & $3 \cdot 0$ & 0.7 & $2 \cdot 6$ & 0.7 & $2 \cdot 7$ & 0.6 & 2.8 & 0.6 & 2.9 & 0.9 \\
\hline & CID2 & 2.4 & 0.6 & 2.5 & 0.7 & 2.6 & 0.8 & 2.4 & 0.7 & $2 \cdot 3$ & 0.4 & 2.7 & 0.6 & 2.4 & 0.3 & 2.3 & 0.7 & 2.4 & 0.8 & 2.6 & 0.8 \\
\hline & CID3 & 2.6 & 0.6 & 2.8 & 0.7 & 2.8 & 0.6 & 2.9 & 0.5 & 2.6 & 0.3 & 3.0 & 0.5 & 2.6 & 0.5 & 2.7 & 0.9 & 2.5 & 0.8 & 2.9 & 0.8 \\
\hline Glucose (mmol/l) & CID1 & 4.9 & 0.8 & 5.0 & 0.6 & $5 \cdot 2$ & 0.7 & 5.4 & 0.9 & 4.7 & 0.4 & 4.8 & 0.4 & 4.8 & 0.5 & $5 \cdot 0$ & 0.5 & 4.8 & $1 \cdot 2$ & 5.0 & 0.6 \\
\hline & CID2 & 4.7 & 0.7 & 4.8 & 0.4 & 4.9 & $1 \cdot 0$ & 4.9 & 0.6 & 4.5 & 0.4 & 4.7 & 0.4 & 4.6 & 0.5 & 4.7 & 0.4 & 4.8 & 0.5 & 4.7 & 0.3 \\
\hline & CID3 & 4.7 & 0.4 & 4.9 & 0.5 & 4.8 & 0.5 & 5.0 & 0.5 & 4.6 & 0.5 & 4.9 & 0.5 & 4.6 & 0.4 & 4.9 & 0.5 & 4.6 & 0.4 & 5.0 & 0.4 \\
\hline Insulin $(\mu \mid \mathrm{U} / \mathrm{ml}) \ddagger$ & CID1 & $9 \cdot 1$ & 4.9 & $10 \cdot 2$ & 6.7 & $10 \cdot 0$ & 5.5 & $15 \cdot 1$ & $10 \cdot 8$ & 8.5 & 3.5 & 8.1 & 3.7 & 7.5 & $2 \cdot 3$ & 8.0 & 3.9 & 10.5 & $7 \cdot 1$ & 9.5 & 3.1 \\
\hline & CID2 & 5.7 & 3.6 & 6.5 & 3.0 & 5.6 & 3.6 & 7.9 & 4.6 & 4.9 & $2 \cdot 8$ & 5.5 & 1.7 & 5.7 & $3 \cdot 1$ & 5.4 & $2 \cdot 2$ & $6 \cdot 8$ & 4.8 & 7.4 & $2 \cdot 2$ \\
\hline & CID3 & $6 \cdot 8$ & 5.3 & 7.9 & 3.8 & 6.8 & $5 \cdot 2$ & 9.9 & 5.4 & 7.8 & 8.0 & 7.4 & $2 \cdot 3$ & $6 \cdot 2$ & 3.9 & 7.0 & $3 \cdot 1$ & 6.4 & 3.4 & 7.5 & 3.1 \\
\hline HOMA-IR $\dagger$ & CID1 & 2.0 & 1.3 & 2.4 & 1.8 & 2.4 & 1.7 & 3.8 & 3.0 & 1.8 & 0.7 & 1.7 & 0.8 & 1.6 & 0.7 & 1.9 & 0.8 & $2 \cdot 3$ & 1.8 & $2 \cdot 1$ & 0.7 \\
\hline & CID2 & 1.2 & 0.9 & 1.4 & 0.8 & 1.3 & 0.9 & 1.8 & $1 \cdot 2$ & 1.0 & 0.6 & 1.1 & 0.4 & $1 \cdot 1$ & 0.6 & 1.1 & 0.5 & 1.5 & 1.3 & 1.5 & 0.5 \\
\hline & CID3 & 1.5 & 1.3 & 1.7 & 0.9 & 1.5 & 1.3 & $2 \cdot 1$ & 1.3 & 1.7 & $2 \cdot 1$ & 1.6 & 0.5 & 1.3 & 0.8 & 1.6 & 0.8 & 1.3 & 0.7 & 1.6 & 0.7 \\
\hline
\end{tabular}

LP, low protein; LGI, low glycaemic index; HGI, high glycaemic index; HP, high protein; WL, continued weight losers; WR, weight regainers; HOMA-IR, homeostasis model assessment of insulin resistance. * Values are from the fasting state.

† Calculated as fasting glucose $(\mathrm{mmol} / \mathrm{l}) \times$ fasting insulin $(\mu \mathrm{lU} / \mathrm{ml}) / 22.5$.

$\ddagger 1 \mu \mathrm{lU} / \mathrm{ml}=6.945 \mathrm{pmol} / \mathrm{l}$. 
compared with the WR group (Table 2). During the weightloss phase, only the fold change in weight was different, although borderline, between the WL $(0.89$ (SD 0.03)) and WR groups (0.90 (SD 0.02) $(P=0.021)$.

As expected from the selection, during the 6-month maintenance phase, all subjects of the WL group lost weight $(3.3(\mathrm{SD} 2 \cdot 2) \mathrm{kg}$ ), while all WR subjects gained weight $(3.9$ $(\mathrm{SD} 1 \cdot 2) \mathrm{kg}$ ). They were different in the CID3:CID2 ratio of all measured adiposity indices $(P<0.001)$. In addition, WL subjects had less increase in diastolic blood pressure $(P=0.035)$, cholesterol $(P=0.044)$, TAG $(P=0.037)$ and glucose $(P=0 \cdot 045)$.

Post-intervention dietary intakes are presented in Table 3. From the dietary recall of about three-quarters of the cohort who had available food records, there was a modest difference in dietary protein $(2.9 \%$ energy $(\% \mathrm{E}))$ and GI (3.5 units) between the LP and HP groups and between the LGI and HGI groups, respectively. Those differences were also detectable in the WL and WR groups, with the exception of protein intake between the HP and LP subjects in the WL group. These differences were confirmed by the urinary $\mathrm{N}$ excretion as a marker of adherence to a HP or LP diet (Table 3).

Further analysis showed that among the pooled subjects, no dietary effect could be detected on the fold change in either body weight or fat mass percentage $(P>0 \cdot 5)$. However, in the WL group, HP intake and LGI were associated with more weight loss $(P=0.014$ and 0.012 , respectively). In the WR group, HP intake was associated with less weight regain $(P=0.001)$, whereas GI had no effect $(P=0 \cdot 7)$. But for fat mass, no significant dietary effect in both groups could be detected $(P>0.5)$.

\section{Blood protein and steroid changes during weight loss and maintenance}

At baseline, after weight loss and after the weight-maintenance period, twenty-nine blood proteins and three steroids were measured (Fig. 2). They were grouped into seven categories based on their functions. Cortisol was listed as an extra category. Except for angiotensinogen (AGT), acylation-stimulating protein and $\mathrm{GH}$, twenty-nine out of thirty-two analytes showed that their changes during weight maintenance were negatively correlated with the changes during weight loss in the pooled subjects (Table 4), suggesting a 'return-back' effect of the body to keep the homeostasis as it was before the weight loss. Especially, the immunoproteins macrophage migration inhibiting factor, C-reactive protein (CRP), haptoglobin and matrix metalloproteinase 9 , the sex hormones follicle-stimulating hormone and luteinising hormone (LH), and the growth factors vascular endothelial growth factor-D and insulin-like growth factor binding protein 1 (IGFBP1) strongly showed this effect, with $r>0.5$ and $P<0.001$. Interestingly, WL and WR subjects showed differences in this return-back effect for some analytes. Leptin (LEP) and pancreatic polypeptide showed this effect significantly more profoundly in the WR group, and GH and TNF- $\alpha$ also had this trend. On the other hand, IL- 6 was affected in the WL group, but not in WR subjects.
Relationships among anthropometrical, physiological and biochemical characteristics

Multivariate data analysis with discriminant principal component analysis showed that the WL and WR groups can be separated completely on the principal component 1 , which accounts for $91 \%$ of the total subject variance and is mainly determined by the weight-maintenance score, weight/BMI, fat mass and waist circumference (Fig. 3(a) and (b)). LEP, CRP, TAG and glucose were also associated with WR, and IGFBP1 was the only associated with WL.

The effect of dietary intervention was minor, as the profiles of LP, HP, LGI and HGI were all close to the origin. WR subjects with LP or HP diets were grouped in a different direction on the principal component 2 , which accounts for $2 \cdot 8 \%$ of the total variance and is mainly determined by CRP, testosterone (TES), retinol-binding protein 4 (RBP4) and fat mass for HP, and glucagon (GCG), adiponectin and LEP for LP (Fig. 3(a) and (b)).

Plasminogen activator inhibitor 1 (PAI1), INS, resistin and LH did not have a loading score $\geq 2$ on these two main components, but had a geometric mean $\geq 3$ for all components. Therefore, these factors also contributed to maximally explain the variance.

\section{Difference in blood profile by weight maintenance and dietary intervention}

Because of the complex interaction of weight maintenance and dietary intervention, multi-way ANOVA taking all factors and their interactions into account was conducted to identify the effect of each factor and of their interactions on the fold change in blood analytes CID3:CID2. Besides this raw model, a controlled model was also analysed with age, weight CID2:CID1 ratio and the CID2:CID1 ratio of the analyte as covariates, because the former two showed to be different with regard to the outcome of weight maintenance, and the latter one was included for controlling the return-back effect that had considerable contribution to the ANOVA model. The results are shown in Table 5 and the supplementary material (available online at http://www.journals.cambridge. org/bjn).

Higher increases in LEP and CRP were positively associated with weight regain in the pooled subjects identified by both raw and controlled models. However, there were some differences among the diets (Fig. 4). Furthermore, LEP positively correlated with fat mass percentage on their fold changes (adjusted for LEP CID2:CID1 ratio) with the diets LP/LGI ( $r$ 0.812, $P<0.001)$, LP/HGI $(r 0.602, P=0.031)$ and HP/LGI ( $r 0.606, P=0.008)$, but not with the diet HP/HGI $(r 0 \cdot 166$, $P=0.510)$. The relationship between the outcome of weight maintenance and the fold change in LEP was lost after extra controlling for the fold change in fat mass (CID3:CID2) in the model. While for CRP, this extra controlling did not make a difference. IGFBP1 had a trend to positively associate with WL $(P=0.034)$, but this trend disappeared after controlling for its CID2:CID1 ratio. 
Table 3. Food intake in dietary groups and weight-maintenance groups post-intervention (after 6-month maintenance intervention) ${ }^{*}$ (Mean values and standard deviations)

\begin{tabular}{|c|c|c|c|c|c|c|c|c|c|c|c|c|c|c|c|}
\hline \multirow[b]{3}{*}{ Dietary protein group } & \multicolumn{5}{|c|}{ Pooled } & \multicolumn{5}{|c|}{ Continued weight losers } & \multicolumn{5}{|c|}{ Weight regainers } \\
\hline & \multicolumn{2}{|c|}{ LP } & \multicolumn{2}{|c|}{$\mathrm{HP}$} & \multirow[b]{2}{*}{$P$} & \multicolumn{2}{|c|}{ LP } & \multicolumn{2}{|c|}{ HP } & \multirow[b]{2}{*}{$P$} & \multicolumn{2}{|c|}{ LP } & \multicolumn{2}{|c|}{$\mathrm{HP}$} & \multirow[b]{2}{*}{$P$} \\
\hline & Mean & SD & Mean & SD & & Mean & SD & Mean & SD & & Mean & SD & Mean & SD & \\
\hline No. of valid/no. total participants & \multicolumn{2}{|c|}{$37 / 48$} & \multicolumn{2}{|c|}{$36 / 48$} & & \multicolumn{2}{|c|}{$19 / 24$} & \multicolumn{2}{|c|}{$17 / 24$} & & \multicolumn{2}{|c|}{$18 / 24$} & \multicolumn{2}{|c|}{$19 / 24$} & \\
\hline Total energy intake $(\mathrm{kJ} / \mathrm{d})$ & 6455 & 2228 & 6815 & 2297 & 0.498 & 5346 & 1913 & 6825 & 2681 & 0.063 & 7625 & 1952 & 6807 & 1967 & 0.213 \\
\hline Carbohydrate (\%E) & $49 \cdot 7$ & 9.7 & $45 \cdot 6$ & 7.4 & $0.046 \dagger$ & $52 \cdot 4$ & $10 \cdot 2$ & $47 \cdot 8$ & 8.1 & 0.144 & 46.9 & 8.7 & $43 \cdot 7$ & $6 \cdot 4$ & 0.200 \\
\hline Fat $(\% \mathrm{E})$ & 31.4 & $8 \cdot 7$ & 32.8 & 8.6 & 0.503 & $27 \cdot 7$ & 6.9 & 30.8 & 9.8 & 0.289 & $35 \cdot 3$ & $8 \cdot 8$ & 34.6 & $7 \cdot 1$ & 0.787 \\
\hline Protein (\%E) & $17 \cdot 8$ & $4 \cdot 1$ & $20 \cdot 7$ & 5.4 & $0.012 \dagger$ & $19 \cdot 4$ & 4.5 & 20.6 & $6 \cdot 3$ & 0.495 & $16 \cdot 2$ & 3.0 & $20 \cdot 8$ & 4.6 & $0.001 \dagger$ \\
\hline Alcohol (\%E) & 1.0 & $2 \cdot 3$ & 0.9 & $2 \cdot 1$ & 0.774 & 0.5 & 1.3 & 0.8 & $2 \cdot 3$ & 0.590 & 1.6 & 2.9 & 0.9 & $2 \cdot 1$ & 0.432 \\
\hline $\mathrm{GI}$ & $58 \cdot 3$ & $5 \cdot 1$ & $57 \cdot 1$ & 4.6 & 0.311 & $58 \cdot 2$ & 5.9 & $55 \cdot 7$ & 4.9 & 0.172 & 58.3 & $4 \cdot 3$ & 58.4 & $4 \cdot 0$ & 0.957 \\
\hline \multirow{3}{*}{$\begin{array}{l}\text { Markers of dietary compliance } \\
\text { No. of valid/no. of total participants } \\
\text { Total } 24 \mathrm{~h} \text { urinary } \mathrm{N} \text { excretion }(\mathrm{g} / \mathrm{d})\end{array}$} & \multirow{2}{*}{\multicolumn{2}{|c|}{$30 / 48$}} & & & & & & & & & & & & & \\
\hline & & & \multicolumn{2}{|c|}{$31 / 48$} & & \multicolumn{2}{|c|}{$14 / 24$} & \multicolumn{2}{|c|}{$15 / 24$} & & \multicolumn{2}{|c|}{$16 / 24$} & \multicolumn{2}{|c|}{$16 / 24$} & \\
\hline & $11 \cdot 8$ & $3 \cdot 3$ & $13 \cdot 8$ & $3 \cdot 3$ & $0.023 \dagger$ & $12 \cdot 5$ & $4 \cdot 3$ & 14 & 3.4 & 0.299 & $11 \cdot 2$ & $2 \cdot 1$ & $13 \cdot 6$ & $3 \cdot 4$ & $0.023 \dagger$ \\
\hline & \multicolumn{2}{|c|}{ LGI } & \multicolumn{2}{|c|}{ HGI } & & \multicolumn{2}{|c|}{ LGI } & \multicolumn{2}{|c|}{ HGI } & & & & & & \\
\hline Dietary GI group & Mean & SD & Mean & SD & $P$ & Mean & SD & Mean & SD & $P$ & Mean & SD & Mean & SD & $P$ \\
\hline No. of valid/no. of total participants & & & & & & & & & & & & & & & \\
\hline Total energy intake $(\mathrm{kJ} / \mathrm{d})$ & 6533 & 2213 & 6741 & 2324 & 0.696 & 5902 & 2176 & 6222 & 2704 & 0.696 & 7234 & 2094 & 7178 & 1916 & 0.933 \\
\hline Carbohydrate (\%E) & $47 \cdot 1$ & $9 \cdot 3$ & $48 \cdot 3$ & 8.5 & 0.558 & $49 \cdot 6$ & $10 \cdot 1$ & 51.0 & 8.7 & 0.654 & 44.4 & 7.5 & $46 \cdot 1$ & 7.9 & 0.506 \\
\hline Fat (\%E) & $32 \cdot 4$ & 8.9 & $31 \cdot 8$ & 8.4 & 0.780 & $29 \cdot 8$ & 8.8 & 28.4 & $8 \cdot 2$ & 0.623 & $35 \cdot 2$ & $8 \cdot 3$ & 34.7 & $7 \cdot 7$ & 0.838 \\
\hline Protein (\%E) & $19 \cdot 9$ & 4.5 & 18.5 & 5.4 & 0.234 & $20 \cdot 2$ & $5 \cdot 2$ & 19.6 & 5.7 & 0.737 & 19.6 & 3.6 & $17 \cdot 6$ & $5 \cdot 1$ & 0.188 \\
\hline Alcohol (\%E) & 0.6 & 1.8 & 1.3 & $2 \cdot 6$ & 0.153 & 0.4 & 1.0 & 1.0 & 2.5 & 0.309 & 0.8 & 2.4 & 1.6 & $2 \cdot 7$ & 0.354 \\
\hline GI & $56 \cdot 0$ & 4.6 & 59.5 & 4.5 & $0.002 \dagger$ & 55.3 & $5 \cdot 2$ & 59.2 & 5.3 & $0.034 \dagger$ & 56.9 & 3.8 & $59 \cdot 7$ & 3.9 & $0.030 \dagger$ \\
\hline
\end{tabular}

LP, low protein; HP, high protein; Gl, glycaemic index; LGI, low glycaemic index, HGI, high glycaemic index

* The group difference was analysed by the $t$ test.

$\dagger$ Values were significantly different $(P<0.05)$. 


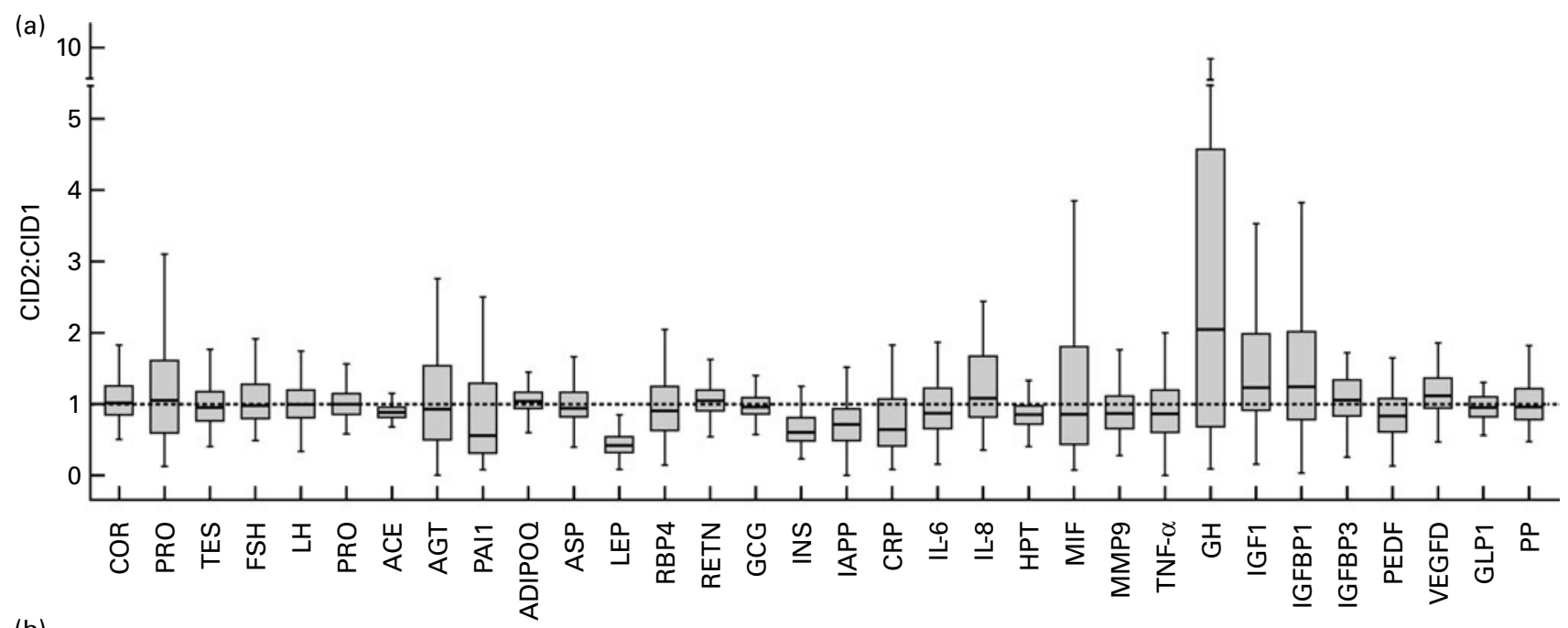

(b)

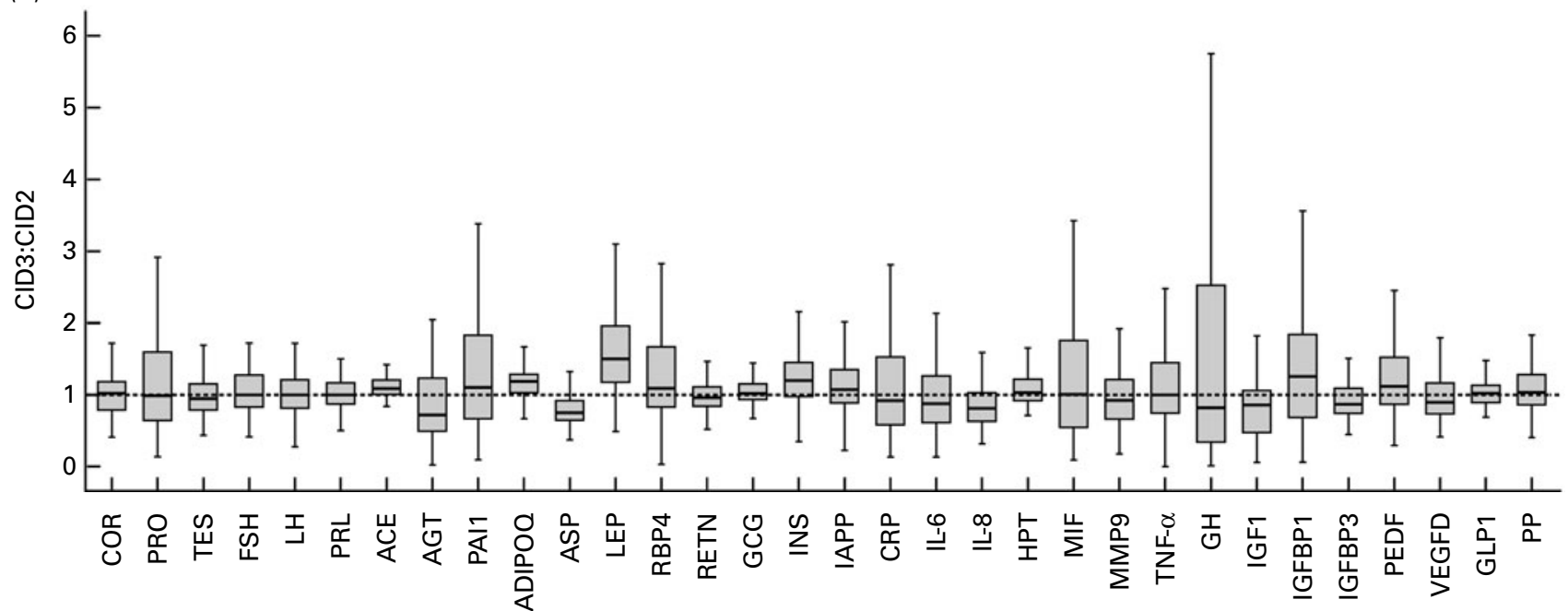

Other Sex hormones $\begin{gathered}\text { Vascular } \\ \text { factors }\end{gathered}$ Adipokines $\begin{gathered}\text { Insulin and } \\ \text { related hormones }\end{gathered} \quad \begin{gathered}\text { Cytokines and } \\ \text { immunoproteins }\end{gathered} \quad$ Growth hormones Satiety

Fig. 2. Fold changes in blood proteins and steroids during (a) weight-loss phase (after 8-week weight loss (CID2):baseline, before weight loss (CID1)) and (b) weight-maintenance phase (after 6-month maintenance intervention (CID3):CID2). Box plot shows the median and interquartile range without outliers of the fold change in each analyte. COR, cortisol; PRO, progesterone; TES, testosterone; FSH, follicle-stimulating hormone; LH, luteinising hormone; PRL, prolactin; ACE, angiotensin I converting enzyme 1; AGT, angiotensinogen; PAl1, plasminogen activator inhibitor-1, active; ADIPOQ, adiponectin; ASP, acylation-stimulating protein; LEP, leptin; RBP4, retinol-binding protein 4; RETN, resistin; GCG, glucagons; INS, insulin; IAPP, islet amyloid polypeptide, amylin, total; CRP, C-reactive protein; HPT, haptoglobin; MIF, macrophage migration inhibiting factor; MMP9, matrix metallopeptidase 9; GH, growth hormone; IGF1, insulin-like growth factor 1; IGFBP1, insulin-like growth factor binding protein 1; IGFBP3, insulin-like growth factor binding protein 3; PEDF, pigment epithelium-derived factor; VEGFD, vascular endothelial growth factor-D; GLP1, glucagon-like peptide-1, total; PP, pancreatic polypeptide.

Higher increases in TES and CRP were related to a HP diet, but these changes were only found in WR subjects. Higher increases in LEP, INS and GCG were related to a LP diet in the pooled subjects.

There was no analyte for which the fold change did significantly reflect the dietary GI level, neither in pooled subjects nor in WL or WR subjects.

When comparing the interaction of dietary protein and GI, the fold changes in AGT, INS, LH, RBP4 and PAI1 showed difference for the combinations of protein and GI levels. Particularly, AGT and PAI1 had differences of more than two-fold among combinations, which remained significant with post hoc testing (see the supplementary material, available online at http://www.journals.cambridge.org/bjn).

Concerning the efficacy of some blood analytes as the biomarker of dietary protein or GI level, there were significant differences between the WL and WR groups. Interestingly, those markers are functionally related. Fold changes in resistin, CRP and haptoglobin, which are influenced by the interaction of weight maintenance and dietary protein level, are (related to) immunoproteins, whereas fold changes in $\mathrm{GH}$ and LH influenced by the interaction of weight maintenance, dietary protein and GI are related to cell growth and development. 
Table 4. Correlations between the fold changes in blood analytes during the weight-loss phase and the weight-maintenance phase* (Correlation coefficients)

\begin{tabular}{|c|c|c|c|c|c|c|c|c|}
\hline \multirow[b]{2}{*}{ Category } & \multirow[b]{2}{*}{ Analyte } & \multicolumn{2}{|c|}{ Pooled } & \multicolumn{2}{|c|}{ WL } & \multicolumn{2}{|c|}{ WR } & \multirow{2}{*}{$\begin{array}{c}\text { Group difference* } \\
P\end{array}$} \\
\hline & & $r$ & $P$ & $r$ & $P$ & $r$ & $P$ & \\
\hline Others & COR & -0.420 & $<0.001 \dagger$ & -0.416 & $0.003 \dagger$ & -0.420 & $0.003 \dagger$ & 0.892 \\
\hline \multirow{5}{*}{ Sex hormones } & $\mathrm{FSH}$ & -0.521 & $<0.001 \dagger$ & -0.569 & $<0.001 \dagger$ & -0.473 & $0.001 \dagger$ & 0.609 \\
\hline & $\mathrm{LH}$ & -0.508 & $<0.001 \dagger$ & -0.598 & $<0.001 \dagger$ & -0.424 & $0.003 \dagger$ & 0.123 \\
\hline & PRO & -0.448 & $<0.001 \dagger$ & -0.478 & $0.001 \dagger$ & -0.411 & $0.004 \dagger$ & 0.813 \\
\hline & TES & -0.286 & $0.005 \dagger$ & -0.288 & $0.047 \dagger$ & -0.324 & $0.028 \dagger$ & 0.849 \\
\hline & PRL & -0.377 & $<0.001 \dagger$ & -0.330 & $0.022 \dagger$ & -0.422 & $0.004 \dagger$ & 0.574 \\
\hline \multirow[t]{3}{*}{ Vascular factors } & ACE & -0.279 & $0.006 \dagger$ & -0.259 & 0.075 & -0.313 & $0.032 \dagger$ & 0.527 \\
\hline & AGT & -0.186 & 0.078 & -0.202 & 0.169 & -0.182 & 0.243 & 0.773 \\
\hline & PAl1 & -0.212 & $0.039 \dagger$ & -0.152 & 0.303 & -0.298 & $0.042 \dagger$ & 0.394 \\
\hline \multirow[t]{5}{*}{ Adipokines } & LEP & -0.430 & $<0.001 \dagger$ & -0.328 & $0.023 \dagger$ & -0.711 & $<0.001 \dagger$ & $<0.001 \ddagger$ \\
\hline & RBP4 & -0.438 & $<0.001 \dagger$ & -0.353 & $0.014 \dagger$ & -0.510 & $<0.001 \dagger$ & 0.167 \\
\hline & ADIPOQ & -0.415 & $<0.001 \dagger$ & -0.225 & 0.125 & -0.493 & $<0.001 \dagger$ & 0.105 \\
\hline & RETN & -0.347 & $0.001 \dagger$ & -0.287 & $0.048 \dagger$ & -0.398 & $0.006 \dagger$ & 0.705 \\
\hline & ASP & -0.079 & 0.448 & -0.200 & 0.177 & 0.001 & 0.994 & 0.239 \\
\hline \multirow[t]{3}{*}{ Insulin and related hormones } & INS & -0.457 & $<0.001 \dagger$ & -0.375 & $0.009 \dagger$ & -0.623 & $<0.001 \dagger$ & 0.365 \\
\hline & IAPP & -0.397 & $<0.001 \dagger$ & -0.395 & $0.007 \dagger$ & -0.465 & $0.002 \dagger$ & 0.616 \\
\hline & GCG & -0.221 & $0.032 \dagger$ & -0.376 & $0.008 \dagger$ & -0.088 & 0.557 & 0.181 \\
\hline \multirow[t]{7}{*}{ Immunoproteins } & CRP & -0.523 & $<0.001 \dagger$ & -0.524 & $<0.001 \dagger$ & -0.528 & $<0.001 \dagger$ & 0.582 \\
\hline & IL-6 & -0.324 & $0.001 \dagger$ & -0.441 & $0.002 \dagger$ & -0.175 & 0.239 & 0.090 \\
\hline & IL-8 & -0.371 & $<0.001 \dagger$ & -0.551 & $<0.001 \dagger$ & -0.215 & 0.147 & 0.334 \\
\hline & HPT & -0.554 & $<0.001 \dagger$ & -0.594 & $<0.001 \dagger$ & -0.533 & $<0.001 \dagger$ & 0.852 \\
\hline & MIF & -0.571 & $<0.001 \dagger$ & -0.506 & $<0.001 \dagger$ & -0.637 & $<0.001 \dagger$ & 0.224 \\
\hline & MMP9 & -0.562 & $<0.001 \dagger$ & -0.560 & $<0.001 \dagger$ & -0.564 & $<0.001 \dagger$ & 0.874 \\
\hline & TNF- $\alpha$ & -0.400 & $<0.001 \dagger$ & -0.219 & 0.159 & -0.496 & $0.001 \dagger$ & 0.067 \\
\hline \multirow[t]{6}{*}{ Growth factors } & $\mathrm{GH}$ & -0.186 & 0.072 & -0.008 & 0.959 & -0.392 & $0.006 \dagger$ & 0.063 \\
\hline & IGF1 & -0.409 & $<0.001 \dagger$ & -0.394 & $0.006 \dagger$ & -0.435 & $0.002 \dagger$ & 0.225 \\
\hline & VEGFD & -0.511 & $<0.001 \dagger$ & -0.555 & $<0.001 \dagger$ & -0.442 & $0.002 \dagger$ & 0.513 \\
\hline & PEDF & -0.373 & $<0.001 \dagger$ & -0.391 & $0.006 \dagger$ & -0.355 & $0.014 \dagger$ & 0.884 \\
\hline & IGFBP1 & -0.525 & $<0.001 \dagger$ & -0.550 & $<0.001 \dagger$ & -0.462 & $0.001 \dagger$ & 0.612 \\
\hline & IGFBP3 & -0.352 & $<0.001 \dagger$ & -0.412 & $0.004 \dagger$ & -0.307 & $0.036 \dagger$ & 0.642 \\
\hline \multirow{2}{*}{ Satiety hormones } & GLP1 & -0.315 & $0.002 \dagger$ & -0.397 & $0.005 \dagger$ & -0.268 & 0.068 & 0.735 \\
\hline & PP & -0.367 & $<0.001 \dagger$ & -0.151 & 0.306 & -0.521 & $<0.001 \dagger$ & $0.049 \ddagger$ \\
\hline
\end{tabular}

WL, continued weight losers; WR, weight regainers; COR, cortisol; FSH, follicle-stimulating hormone; LH, luteinising hormone; PRO, progesterone; TES, testosterone; PRL, prolactin; ACE, angiotensin I converting enzyme 1; AGT, angiotensinogen; PAI1, plasminogen activator inhibitor-1, active; LEP, leptin; RBP4, retinol-binding protein 4; ADIPOQ, adiponectin; RETN, resistin; ASP, acylation-stimulating protein; INS, insulin; IAPP, islet amyloid polypeptide, amylin, total; GCG, glucagons; CRP, C-reactive protein; HPT, haptoglobin; MIF, macrophage migration inhibiting factor; MMP9, matrix metallopeptidase 9; GH, growth hormone; IGF1, insulin-like growth factor 1; VEGFD, vascular endothelial growth factor-D; PEDF, pigment epithelium-derived factor; IGFBP3, Insulin-like growth factor binding protein 3; GLP1, glucagon-like peptide-1, total; PP, pancreatic polypeptide.

* Pearson's correlation analysis on In after 8-week weight loss (CID2):baseline, before weight loss (CID1) v. In after 6-month weight maintenance:CID2. The difference between the WL and WR groups on the correlation slope was compared by ANOVA with the interaction of group ID (WL or WR) and CID2:CID1 as a covariate.

$\dagger$ Correlation was significant different $(P<0.05)$.

$\ddagger$ Correlations were significantly different between WL and WR $(P<0.05)$.

\section{Discussion}

The present data showed that the changes in measured proteins and steroid hormones during the weight-maintenance phase largely depend on their changes during the weightloss phase, indicating that the body is trying to return to the original homeostatic state. This process also occurred in the WL group, even though their weight and fat mass continued to decrease. The energy state changing from negative during weight loss to balanced during weight maintenance might be the driving force of this process. Such a return-back effect on blood protein and steroid hormones is in line with a previously observed 'reversal effect' on blood lipids, glucose and INS during weight-loss maintenance ${ }^{(15,16)}$. In contrast to the WR group, the WL group showed the ability to recall the pre-weight-loss state of IL-6 and to readily reach new states for LEP, pancreatic polypeptide, GH and TNF- $\alpha$. For LEP as the most important indicator of body fat, it is not surprising that it showed a different pattern between the WL and WR groups concerning this process. It is also reasonable that pancreatic polypeptide as an appetite-regulating hormone that influences energy intake ${ }^{(17)}$ was different. Furthermore, it is known that GH has an abnormal metabolism in obesity ${ }^{(18)}$, of which the mechanism is not clear ${ }^{(19)}$. Here, we observed an increase in GH during weight loss followed by a decrease in WR but a stable level in WL during maintenance. However, because of the large inter-individual variation of $\mathrm{GH}$ we must be careful in drawing a conclusion. The other two cytokines are both related to obesity ${ }^{(20)}$, but return-back regulation of IL-6 failed in the WR group while that of TNF- $\alpha$ did not. The present observations imply that the process controlling the transition of these proteins to a new homeostatic state seems to be different between the WL and WR groups, which warrants further investigations.

The discriminant principal component analysis showed that the WR and WL groups were mainly distinguished by body 


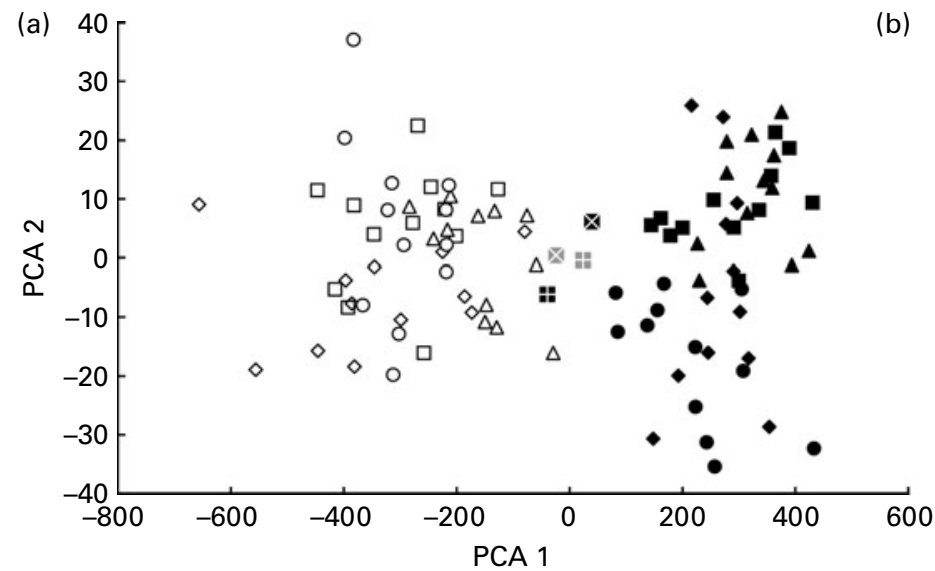

(b)

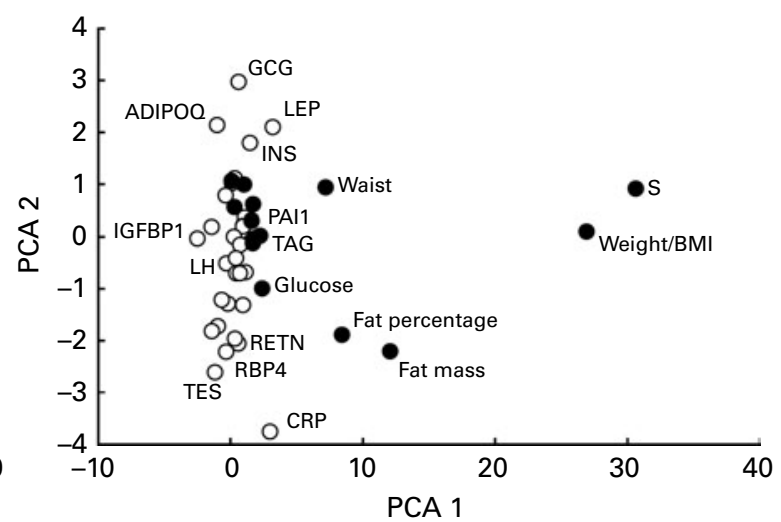

Fig. 3. Discriminant principal component analysis (PCA) of the subjects in weight maintenance $\times$ diet groups on the fold changes in anthropometrical, physiological

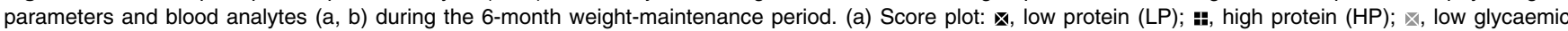

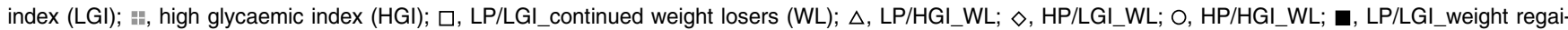
ners (WR); $\Delta$, LP/HGI_WR; $\bullet$ HP/LGI_WR; $\bullet$, HP/HGI_WR. (b) Loading plot: the top eighteen variables with a loading score $>3$ are indicated. S, weightmaintenance score; GCG, glucagon; ADIPOQ, adiponectin; LEP, leptin; INS, insulin; PAl1, plasminogen activator inhibitor-1, active; IGFBP1, insulin-like growth factor binding protein 1; LH, luteinising hormone; RETN, resistin; RBP4, retinol-binding protein 4; TES, testosterone; CRP, C-reactive protein. O, Blood proteins and steroids; $\bullet$, anthropometrical and physiological parameters.

anthropometrical parameters, but not much by the blood analytes, at least for this 6-month period. The blood profile reflected the diet intervention profile more than weight maintenance. Nevertheless, the differences between the high and low dietary protein or GI levels were modest in the present study, which is in line with the conclusion from the whole Diogenes study ${ }^{(9)}$.

The important contributors identified by discriminant principal component analysis were confirmed by ANOVA. However, in ANOVA, we corrected for the changes during the weightloss phase, which allowed us to focus on the real effects from different diets or by weight maintenance. Therefore, we used the results from ANOVA to identify blood biomarkers. In this way, LEP and CRP were the only two proteins significantly associated with weight regain. Although these two proteins are well recognised as obesity biomarkers, the present results provide additional details about the effect of the dietary components.

LEP is primarily released by adipocytes ${ }^{(21)}$ and its circulating level reflects the amount of adipose tissue in the body. Therefore, it is logical that LEP is a biomarker of WR due to regained fat mass, as observed by others ${ }^{(22)}$. Interestingly, although their fat mass increased similarly as with other diets, the WR group with the HP/HGI diet failed to increase LEP more than the WL group with the same diet. LEP did not follow the change in body fat mass, implying that abnormal regulation occurs on the secretion of LEP in proportion to the fat mass with this diet. A previous study has shown that a HP diet blunts the increase in LEP during weight maintenance compared with LP diets, done with a $20 \%$ higher protein intake $(18 \% \quad v, 15 \% \mathrm{E})$ for a 3-month weight-maintenance period $^{(23)}$. A HP diet is suggested to stimulate the central nervous system LEP sensitivity to compensate for the decrease in LEP level and to sustain reduction in appetite and weight ${ }^{(24)}$. However, another study could not significantly demonstrate this effect of a HP diet $(25 \% v, 15 \% \mathrm{E})$ for a comparable weight-maintenance period ${ }^{(25)}$. We also observed a trend for the influence of GI on the effect of HP (interaction $P=0.074$ ), namely that only with HGI there is a lowering effect of diet protein $(P=0.015)$ on the change in LEP. On the other hand, with HGI there is also an enhancing effect of weight regain $(P=0 \cdot 020)$ on the change in LEP. Therefore, with the combination diet HP/HGI, there was no apparent difference between the WR and WL groups. This complex interaction between diet GI and weight-maintenance performance may explain the inconsistencies in previous studies and suggests that GI may influence the signalling of LEP in the brain.

Although CRP is not an adipokine, it is strongly associated with total and abdominal, subcutaneous and visceral adiposity, especially in pre-menopausal women ${ }^{(26,27)}$. CRP increased during the weight-maintenance phase only with a HP diet in the WR group. This interaction between diet protein and the outcome of weight maintenance has not been reported before. This finding may explain the discrepancy between the present result and those from others. Due et $a{ }^{(28)}$ did not find the effect of a HP diet on CRP and other acute-phase proteins, possibly because their subjects all lost weight in a 6-month weight-control programme. Other studies have reported CRP to be decreased by a HP $\operatorname{diet}^{(29)}$, but in those studies, the effects of weight loss and dietary protein level were not dissected. We did not observe an effect of HP on CRP in weight losers, but in the present case, this could be due to the fact that there was only slight difference in dietary protein intake in HP and LP subjects in the WL group (Table 3).

CRP is produced by the liver, and it is known that liver function can be affected by dietary protein level as has been demonstrated for the hepatic gluconeogenesis ${ }^{(30)}$. Production of CRP can be induced by adipocytokines including IL- 6 and TNF- $\alpha^{(31)}$, but in the present study the HP diet had no effect 
Table 5. Summary of blood analytes* that are associated with the outcome of weight maintenance and dietary intervention†

\begin{tabular}{|c|c|c|c|c|c|c|c|c|c|c|}
\hline \multirow[b]{3}{*}{ Category } & \multirow[b]{3}{*}{ Analyte } & \multirow[b]{3}{*}{ Model } & \multirow{3}{*}{$\begin{array}{l}\text { Maintenance } \\
\text { Pooled }\end{array}$} & \multicolumn{5}{|c|}{ Dietary intervention } & \multirow{3}{*}{$\begin{array}{c}\text { Maintenance } \times \text { protein } \\
\text { Pooled }\end{array}$} & \multirow{3}{*}{$\begin{array}{c}\text { Maintenance } \times \text { protein } \times G \\
\text { Pooled }\end{array}$} \\
\hline & & & & \multicolumn{2}{|c|}{ Protein } & \multicolumn{3}{|c|}{ Protein $\times$ Gl } & & \\
\hline & & & & Pooled & WR & Pooled & WL & WR & & \\
\hline \multirow[t]{4}{*}{ Sex hormones } & TES & Raw & & $\mathrm{HP}$ & $\mathrm{HP}$ & & & & & \\
\hline & & Controlled & & $\mathrm{HP}$ & $\mathrm{HP}$ & & & & & \\
\hline & LH & Raw & & & & & & & & HP/LGI_WR (LP/LGI_WR) \\
\hline & & Controlled & & & & & & HP/LGI (LP/LGI) & & \\
\hline \multirow[t]{3}{*}{ Vascular factors } & PAl1 & $\begin{array}{l}\text { Raw } \\
\text { Controlled }\end{array}$ & & & & HP/HGI (HP/LGI) & $\begin{array}{l}\mathrm{HP} / \mathrm{HGI} \text { (HP/LGI) } \\
\mathrm{HP} / \mathrm{HGl}(\mathrm{HP} / \mathrm{LGI})\end{array}$ & & & \\
\hline & AGT & Raw & & & & & & HP/LGI (LP/LGI) & & \\
\hline & & Controlled & & & & HP/LGI (LP/LGI) & & HP/LGI (LP/LGI) & & \\
\hline \multirow[t]{4}{*}{ Adipokines } & LEP & Raw & WR & & & & & & & \\
\hline & & Controlled & WR & LP & & & & & & \\
\hline & RETN & $\begin{array}{l}\text { Raw } \\
\text { Controlled }\end{array}$ & & & & & & & HP_WR & \\
\hline & RBP4 & $\begin{array}{l}\text { Raw } \\
\text { Controlled }\end{array}$ & & & & & LP/HGI & & & \\
\hline \multirow[t]{2}{*}{$\begin{array}{l}\text { Insulin and } \\
\text { related hormones }\end{array}$} & INS & $\begin{array}{l}\text { Raw } \\
\text { Controlled }\end{array}$ & & LP & & & & $|P / H G|$ & & \\
\hline & GCG & $\begin{array}{l}\text { Raw } \\
\text { Controlled }\end{array}$ & & LP & LP & & & & & \\
\hline \multirow[t]{3}{*}{ Immunoproteins } & CRP & Raw & WR & & $\mathrm{HP}$ & & & & HP_WR & \\
\hline & & Controlled & WR & $\mathrm{HP}$ & $\mathrm{HP}$ & & & & & \\
\hline & HPT & $\begin{array}{l}\text { Raw } \\
\text { Controlled }\end{array}$ & & & & & & & HP WR & \\
\hline Growth factors & $\mathrm{GH}$ & $\begin{array}{l}\text { Raw } \\
\text { Controlled }\end{array}$ & & & & & & & & HP/LGI_WL \\
\hline
\end{tabular}

GI, glycaemic index; WR, weight regainers; WL, continued weight losers; TES, testosterone; HP, high protein; LH, luteinising hormone; LGI, low Gl; LP, low protein; PAl1, plasminogen activator inhibitor-1, active; HGI, high Gl; AGT, angiotensinogen; LEP, leptin; RETN, resistin; RBP4, retinol-binding protein 4; INS, insulin; GCG, glucagons; CRP, C-reactive protein; HPT, haptoglobin; GH, growth hormone.

* Significant association $(P<0.03)$ in the multi-way ANOVA of the fold change (In after 6-month weight maintenance:after 8-week weight loss (CID2)) in the blood analytes in pooled, or the WL or WR group, without (raw) or with weight-loss (CID1) ratio and the CID2:CID1 ratio of the analyte as covariates.

† The conditions positively associated with the higher/highest fold change in the blood analyte are indicated. The conditions positively associated with the lowest fold change are also indicated in parentheses. 

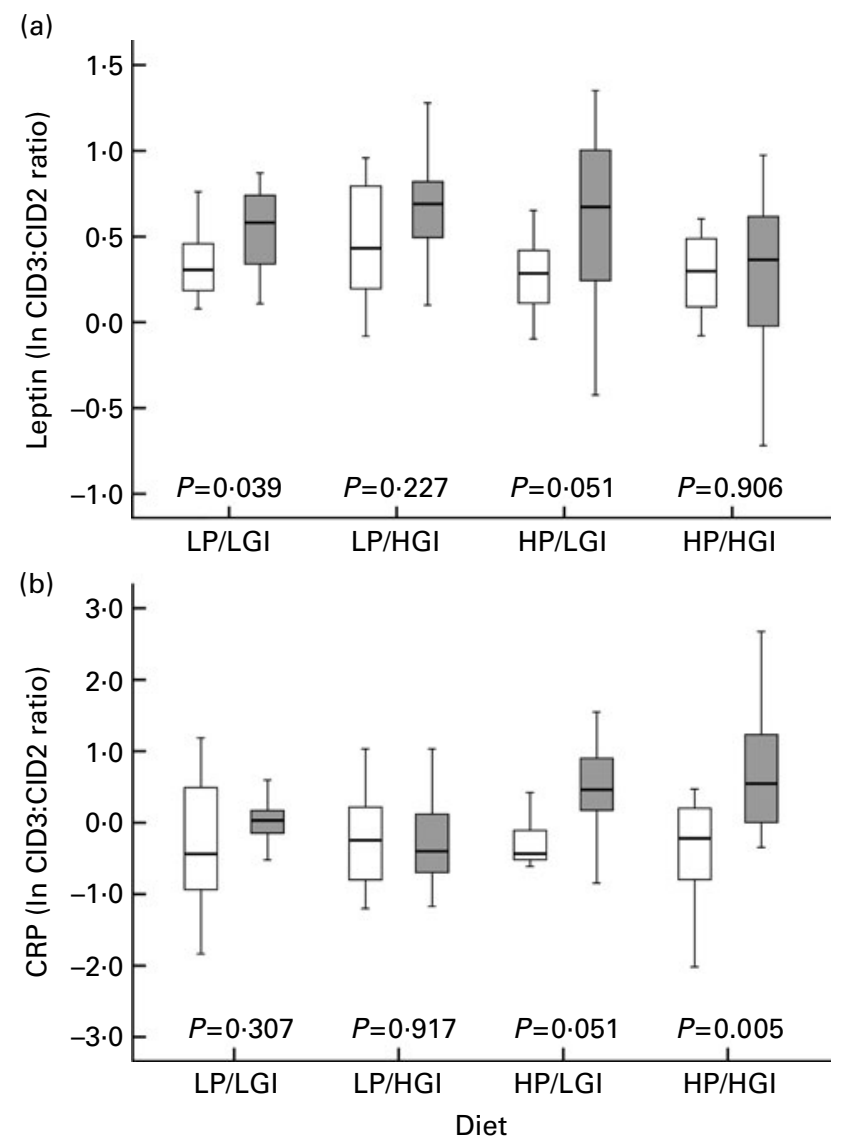

Fig. 4. Box plots of the fold changes during the 6-month weight maintenance (after 6-month maintenance intervention (CID3):after 8-week weight loss (CID2)) of (a) leptin and (b) C-reactive protein (CRP) with respect to weight maintenance and diet. Blank box represents the continued weight-losers group and grey box, the weight-regainers group. The difference between these two groups with each diet was analysed by the $t$ test on In-transformed values and the $P$ values are listed. Values are median and interquartile range without outliers represented by boxplot. LP, low protein; HP, high protein; LGI, low glycaemic index; HGI, high glycaemic index.

on the blood level of those factors. Thus, we speculate that the HP intake can enhance the sensitivity for adipocytokines to stimulate the production of CRP from the liver. Besides CRP, the other two proteins that showed significant interaction between diet protein and maintenance with a similar pattern, haptoglobin and resistin, are also related to the immune system. As with CRP, haptoglobin is also mainly secreted from the liver ${ }^{(32)}$. Interestingly, a study in mice has suggested that a HP diet provokes a more profound response of the immune system to an infection than a LP diet ${ }^{(33)}$. This augments the link between the immune system and the HP diet. Finally, because CRP is a predictor of $\mathrm{CVD}^{(34)}$, the risk to increase the CRP concentration by weight regain with a HP diet needs confirmation and further investigation on a longer term and in a larger population.

An increase in TES has not been linked to the dietary protein level before. TES is an anabolic hormone. A few studies have pointed out that protein nutrition attenuates the increase in TES by resistance training ${ }^{(35,36)}$. The present data suggest that a HP diet may prevent the body from going into a catabolic state during weight maintenance. In addition, TES acts to increase lipolysis and its administration in males induced a loss of adipose tissue in the $\operatorname{leg}^{(37)}$.

INS and GCG were identified as biomarkers of a LP diet. This finding is not in line with the concept that elevated postprandial amino acids stimulate INS and GCG secretion ${ }^{(38)}$. However, as a high level of carbohydrate is part of the LP diet, they could as well be biomarkers of a high-carbohydrate diet, which would fit well with the main function of these two hormones in the carbohydrate metabolism.

Compared with dietary protein, differences in GI had less effect on the blood profile of examined proteins and steroids. However, several analytes were significantly influenced by the interaction between protein and GI, especially PAI1, AGT and LH. The dietary effect of protein and GI on AGT and LH has not been reported in human subjects, and therefore the present results require further validation. The present finding that PAI1 is repressed by the LGI diet is in line with a study in non-diabetic obese women ${ }^{(39)}$. In that study, this effect was observed with $12-15 \% \mathrm{E}$ protein in the $\operatorname{diet}^{(39)}$. We observed this effect in combination with the HP diet in WL subjects, which is somehow surprising because of the small difference in protein intake between the LP and HP groups among the WL subjects. PAI1 is not only a vascular factor playing an important role in thrombosis, but is also involved in the regulation of the extracellular matrix of adipocytes and may play a positive role in the development of adipocytes ${ }^{(40)}$. Suppression of PAI1 may therefore inhibit adipose tissue development, explaining the relationship between HP/LGI intake and weight loss during the weight-maintenance phase ${ }^{(9)}$.

In summary, the blood protein and steroid measurements indicate that the WL and WR groups during the maintenance phase differ in the process controlling adaptation to a new homeotic state. In addition, our measurements indicate that a HP diet may be beneficial to prevent weight regain and reduce adipose tissue growth by lowering GCG and INS, and by enhancing the anabolic state and lipolysis via TES. Furthermore, the diet HP in combination with the diet LGI has an inhibiting effect on weight regain by lowering the plasma level of PAI1, a modulator of adipose tissue development. However, the effect of the HP diet on body weight could not be confirmed by the present data on fat mass, perhaps due to limited sample size of this Diogenes subcohort. Finally, the increased CRP level in weight regainers on a HP diet may point to a potential health risk.

The present observations were obtained in women with limited sample size as a result of the careful phenotypic selection and the analytical feasibility. Therefore, further studies in men are needed and validation in a larger cohort. Because of our limited sample size and stringent cut-off criteria, we may have missed some true biomarkers. As such, the present findings provide leads for further investigation to better understand the process of weight maintenance.

\section{Acknowledgements}

The Diogenes project was supported by a contract (FP6-2005513946) from the European Commission Food Quality and 
Safety Priority of the Sixth Framework Program. The authors' contributions were as follows: E. C. M. M., P. W., A. A. and W. H. M. S. designed the study; M. A. v. B., L. G. R., S. A. J., A. F. H. P., J. A. M., T. H.-D., A. K. and P. H. conducted the intervention and collected the samples; P. W., F. G. B., S. v. O., W. K. W. H. W. and M. R. A. analysed the blood samples; P. W. and C. H. analysed the data; P. W. and E. C. M. M. drafted the manuscript. All authors read and approved the final manuscript. The authors declare that there is no conflict of interest.

\section{References}

1. Flegal KM, Carroll MD, Ogden CL, et al. (2010) Prevalence and trends in obesity among US adults, 1999-2008. JAMA 303, 235-241

2. International Association for the Study of Obesity, Adult overweight and obesity in the European Union (EU27), Switzerland. http://www.iotf.org/database/documents/ECO versionAdultEU27Switzerland.pdf (accessed 29 June 2010).

3. Wing RR \& Phelan S (2005) Long-term weight loss maintenance. Am J Clin Nutr 82, 222S-225S.

4. Turk MW, Yang K, Hravnak M, et al. (2009) Randomized clinical trials of weight loss maintenance: a review. J Cardiovasc Nurs 24, 58-80.

5. Westerterp-Plantenga MS, Nieuwenhuizen A, Tome D, et al. (2009) Dietary protein, weight loss, and weight maintenance. Annu Rev Nutr 29, 21-41.

6. Du H, Van der AD \& Feskens EJ (2006) Dietary glycaemic index: a review of the physiological mechanisms and observed health impacts. Acta Cardiol 61, 383-397.

7. Moore CS, Lindroos AK, Kreutzer M, et al. (2010) Dietary strategy to manipulate ad libitum macronutrient intake, and glycaemic index, across eight European countries in the Diogenes Study. Obes Rev 11, 67-75.

8. Larsen TM, Dalskov S, van Baak M, et al. (2010) The Diet, Obesity and Genes (Diogenes) Dietary Study in eight European countries - a comprehensive design for long-term intervention. Obes Rev 11, 76-91.

9. Larsen TM, Dalskov S, van Baak MA, et al. (2010) Diets with high or low protein content and glycemic index for weight-loss maintenance. $N$ Engl J Med 363, 2102-2113.

10. Liotta LA, Ferrari M \& Petricoin E (2003) Written in blood. Nature 425, 905-905.

11. Wang P, Holst C, Andersen MR, et al. (2011) Blood profile of proteins and steroid hormones predicts weight change after weight loss with interactions of dietary protein level and glycemic index. PLoS One 6, e16773.

12. Marquez-Quinones A, Mutch DM, Debard C, et al. (2010) Adipose tissue transcriptome reflects variations between subjects with continued weight loss and subjects regaining weight 6 mo after caloric restriction independent of energy intake. Am J Clin Nutr 92, 975-984.

13. Benjamini Y \& Hochberg Y (1995) Controlling the false discovery rate: a practical and powerful approach to multiple testing. J R Stat Soc Series B Stat Methodol 57, 289-300.

14. R Development Core Team (2009) $R$ : A Language and Environment for Statistical Computing. Vienna: R Foundation for Statistical Computing.

15. Sjostrom L, Rissanen A, Andersen T, et al. (1998) Randomised placebo-controlled trial of orlistat for weight loss and prevention of weight regain in obese patients. European Multicentre Orlistat Study Group. Lancet 352, 167-172.
16. Sjostrom CD, Lissner L \& Sjostrom L (1997) Relationships between changes in body composition and changes in cardiovascular risk factors: the SOS Intervention Study. Swedish Obese Subjects. Obes Res 5, 519-530.

17. Cummings DE \& Overduin J (2007) Gastrointestinal regulation of food intake. J Clin Invest 117, 13-23.

18. Scacchi M, Pincelli AL \& Cavagnini F (1999) Growth hormone in obesity. Int J Obes 23, 260-271.

19. Kreitschmann-Andermahr I, Suarez $\mathrm{P}$, Jennings $\mathrm{R}$, et al. (2010) GH/IGF-I regulation in obesity - mechanisms and practical consequences in children and adults. Horm Res Paediatr 73, 153-160.

20. Rankinen T, Zuberi A, Chagnon YC, et al. (2006) The human obesity gene map: the 2005 update. Obesity (Silver Spring) 14, 529-644.

21. Moreno-Aliaga MJ, Lorente-Cebrian S \& Martinez JA (2010) Regulation of adipokine secretion by $n-3$ fatty acids. Proc Nutr Soc 69, 324-332.

22. Vogels N \& Westerterp-Plantenga MS (2007) Successful long-term weight maintenance: a 2-year follow-up. Obesity 15, 1258-1266

23. Westerterp-Plantenga MS, Lejeune M, Nijs I, et al. (2004) High protein intake sustains weight maintenance after body weight loss in humans. Int J Obes 28, 57-64.

24. Weigle DS, Breen PA, Matthys CC, et al. (2005) A highprotein diet induces sustained reductions in appetite, ad libitum caloric intake, and body weight despite compensatory changes in diurnal plasma leptin and ghrelin concentrations. Am J Clin Nutr 82, 41-48.

25. Claessens M, van Baak MA, Monsheimer S, et al. (2009) The effect of a low-fat, high-protein or high-carbohydrate ad libitum diet on weight loss maintenance and metabolic risk factors. Int J Obes 33, 296-304.

26. Cartier A, Cote M, Lemieux I, et al. (2009) Sex differences in inflammatory markers: what is the contribution of visceral adiposity? Am J Clin Nutr 89, 1307-1314.

27. Rexrode KM, Pradhan A, Manson JE, et al. (2003) Relationship of total and abdominal adiposity with CRP and IL- 6 in women. Ann Epidemiol 13, 674-682.

28. Due A, Toubro S, Stender S, et al. (2005) The effect of diets high in protein or carbohydrate on inflammatory markers in overweight subjects. Diabetes Obes Metab 7 , 223-229.

29. Abete I, Astrup A, Martinez JA, et al. (2010) Obesity and the metabolic syndrome: role of different dietary macronutrient distribution patterns and specific nutritional components on weight loss and maintenance. Nutr Rev 68 , $214-231$.

30. Linn T, Santosa B, Gronemeyer D, et al. (2000) Effect of long-term dietary protein intake on glucose metabolism in humans. Diabetologia 43, 1257-1265.

31. Gabay C \& Kushner I (1999) Acute-phase proteins and other systemic responses to inflammation. N Engl J Med $\mathbf{3 4 0}$, 448-454.

32. Patel L, Buckels AC, Kinghorn IJ, et al. (2003) Resistin is expressed in human macrophages and directly regulated by PPAR gamma activators. Biochem Biophys Res Commun 300, 472-476.

33. Oarada M, Kamei K, Gonoi T, et al. (2009) Beneficial effects of a low-protein diet on host resistance to Paracoccidioides brasiliensis in mice. Nutrition 25, 954-963.

34. Danesh J, Wheeler JG, Hirschfield GM, et al. (2004) C-reactive protein and other circulating markers of inflammation in the prediction of coronary heart disease. $N$ Engl J Med 350, 1387-1397. 
35. Hulmi JJ, Ahtiainen JP, Selanne H, et al. (2008) Androgen receptors and testosterone in men - effects of protein ingestion, resistance exercise and fiber type. J Steroid Biochem Mol Biol 110, 130-137.

36. Chandler RM, Byrne HK, Patterson JG, et al. (1994) Dietary supplements affect the anabolic hormones after weighttraining exercise. $J$ Appl Physiol 76, 839-845.

37. Woodhouse LJ, Gupta N, Bhasin M, et al. (2004) Dose-dependent effects of testosterone on regional adipose tissue distribution in healthy young men. J Clin Endocrinol Metab 89, 718-726.
38. Promintzer M \& Krebs M (2006) Effects of dietary protein on glucose homeostasis. Curr Opin Clin Nutr Metab Care 9, 463-468

39. Jensen L, Sloth B, Krog-Mikkelsen I, et al. (2008) A lowglycemic-index diet reduces plasma plasminogen activator inhibitor-1 activity, but not tissue inhibitor of proteinases-1 or plasminogen activator inhibitor-1 protein, in overweight women. Am J Clin Nutr 87, 97-105.

40. Mariman EC \& Wang P (2010) Adipocyte extracellular matrix composition, dynamics and role in obesity. Cell Mol Life Sci 67, 1277-1292. 